

\title{
Effect of the Nature of Ceratophyllum demersum Extracts on Lactuca sativa Seedlings
}

\author{
José Luis Viveros-Legorreta',2, S. S. S. Sarma², Leonor Angelica Guerrero-Zúñiga ${ }^{3}$ and \\ Angelica Rodríguez-Dorantes ${ }^{1 *}$
}

${ }^{1}$ Laboratorio de Fisiología Vegetal, Departamento de Botánica, Escuela Nacional de Ciencias Biológicas, Instituto Politécnico Nacional, México City 11340, México

${ }^{2}$ Laboratorio de Zoología Acuática, Facultad de Estudios Superiores, Iztacala, Universidad Autónoma de México, Los Reyes Iztacala s/n, México

3Instituto Mexicano del Petróleo, México City o7730, México

*Corresponding author.

\begin{abstract}
Some authors suggest the use of plant homogenates or extracts to test for allelopathy; those include the employment of fresh or dried macrophytes homogenized with water or moderate lipophilic solvents such as methanol, ethanol and acetone are also appropriate to extract more lipophilic compounds. Bioassays of aqueous plant extracts suggested that phytotoxins are directly released by the plant residues. A number of characteristics is important when choosing a bioassay including species, growth form and phenology; particularly, germination and seedling development are the more appropriate life stage to apply for studies about elemental allelopathy. The present study evaluated the bioactivity of aqueous and acetone extracts from Ceratophyllum demersum L. on Lactuca sativa L. seedlings with regard to their phytotoxic effect. The comparison of the NRPGI (Residual Percentage of Germinated Seeds Index) and NRERI (Normalized Residual Elongation Root Index) that allows the analysis of extracts' toxicity, showed the effect of two kinds of Ceratophyllum demersum extracts: aqueous and 50\% acetone extracts and the presence of active compounds that inhibited and promoted the first stage of development in Lactuca sativa seedlings, indicating doses with low or moderate toxicity and hormesis on this plant species.
\end{abstract}

\section{Article Info \\ Accepted: 22 June 2016 \\ Available Online: 06 July 2016}

Keywords

Allelopathy

Ceratophyllum demersum

Lactuca sativa

Phytotoxicity

\section{Introduction}

Allelopathy is defined as the science that studies any process involving secondary metabolites produced by plants, algae, bacteria, and fungi that influence the growth and development of agricultural and biological systems, Gopal and Goel (1993) and Gross (1999) mention that this definition includes both beneficial and detrimental effects caused by these allelochemicals in the surrounding organisms and may be an adaptive strategy of submersed macrophytes. Gross et al. (2007) suggest the use of plant homogenates or extracts to test for allelopathy; those include the employ of fresh or dried macrophytes homogenized with water, incubated for a certain period, filtered and then the filtrate is added to target organisms. Thus, bioassays of aqueous plant extracts suggested that phytotoxins are directly released by the plant residues. Gross (1999) also mentions that the employ of moderately lipophilic solvents such as methanol, ethanol and acetone or mixtures of those solvents with water are also appropriate to extract more lipophilic compounds that have a low molecular weight, 
are fairly water-soluble and can bind to or pass through cell membranes. Extract-based methods offer the chance to compare the allelopathic potential of different macrophyte species in a standardized way. There are some bioassay-directed extractions of aquatic plants like Ceratophyllum demersum, Elodea spp., Myriophyllum spp., Najas marina and Stratiotes aloides with different solvents and solvent mixtures (water, methanol, and acetone; pure or mixed with water), that revealed the highest activity of these plants particularly against cyanobacteria (Gross et al., 1996, 2003; Erhard and Gross, 2006; Mulderij et al., 2007). Macías et al. (2008) noted that the first problem faced when studying allelopathy of aquatic plants is choosing the appropriate target organisms and the methodology for bioassays; data obtained with commonly used and highly sensitive species such as lettuce and duckweed (Elakovich, 1999) do not necessarily reflect the complex interactions among the organisms living in a certain ecosystem or niche, even though they can provide valuable preliminary data in a simple way. A number of characteristics is important when choosing a bioassay including species, growth form, and phenology; Morris et al. (2009) and Callaway and Ridenour (2004) recommend species that are not normally associated with an allelopathic plant and these may be more sensitivity to the effects from allelopathy than one that has co-evolved with the species. Fletcher and Renney (1963) and Nasir et al. (2005) suggest the employ of agronomic species, which have been used as bioassays in many studies of biochemical allelopathy; particularly, germination and seedling development are the more appropriate life stage to apply for studies about elemental allelopathy. Elakovich and Wooten (1989) analyzed the effect of 17 extracts of aquatic and wetland plants against lettuce and founded these plants significantly reduced lettuce seedling growth. Espen et al. (1997); Mishra and Choudhuri (1998) and Tiqua et al. (1996), showed that the most evident effects of toxic compounds on plants were inhibition of seed germination and root growth. The measurement of seed germination rate and root elongation of different plants are the most values employed in phytotoxicity assays (Sharifi et al., 2007; Valerio et al., 2007; Chen et al., 2010; Kočí et al., 2010). Visioli et al. (2014) noted that OECD (Organisation for Economic Co-operation and Development), US-EPA (US-Environmental Protection Agency) and US-FDA (US-Food and Drug Administration), recommend the most sensitive dicotyledons species: Cucumis sativus, Lactuca sativa, Raphanus sativus, Trifolium pratensis, and monocotyledons species: Triticum aestivum and Panicum miliaceum tested by diverse authors (Fletcher et al., 1988; Wang et al., 2001; Di Salvatore et al., 2008; Ling et al., 2010).

Ceratophyllum demersum L., may grow in water depths between 0.5 to $8.5 \mathrm{~m}$, inhabiting deeper water where only $1 \%$ of the surface illumination is available (Hutchinson, 1975); metabolic excretions of $C$. demersum inhibited the growth of several nitrogen-fixing cyanobacteria (Kogan and Chinnova, 1972) and Wium-Andersen et al. (1983) suggested the role of elemental sulphur or a labile sulphur compound as allelopathically active substance(s). It is known that exuded allelochemicals and compounds extracted from $C$. demersum inhibited cyanobacteria (Jasser, 1994, 1995; Körner and Nicklisch, 2002) and Gross et al. (2003) mention that more than one kind of active allelopathic substance that might be both hydrophobic and hydrophilic was found in this species.

The present study evaluated the bioactivity of aqueous and acetone extracts from Ceratophyllum demersum L. on Lactuca sativa L. seedlings regarding to their phytotoxic effect.

\section{Materials and methods}

\section{Collection of macrophyte}

Ceratophyllum demersum L. submerged plants $(30 \mathrm{~cm}$ height including rhizoids) were collected from field populations in "Laguna de Salazar", located inside Parque Nacional Miguel Hidalgo y Costilla, near the Municipios of Lerma, Ocoyoacac y Huixquilucan $\left(99^{\circ}\right.$ $19^{\prime} 40^{\prime \prime} \mathrm{N}$ y $99^{\circ} 23^{\prime} 35^{\prime \prime} \mathrm{W}$ ), at the East of México City. Plants were deposited inside sterile plastic bags and transported in ice to the laboratory, washed with distilled water to eliminate the sediment adhered to the rhizoids and keep them cold. All the fresh biomass was weighed and made a composite sample from the plants collected, to obtain the aqueous and acetone extracts, according to Quayyum et al. (1999) and Gross et al. (2003) methods as follows.

\section{Aqueous extract procedure}

Thirty grams of fresh $C$. demersum biomass were homogenized in mortar and pestle until obtain a soft plant mass. Distilled sterile water was added to this biomass ( $2 \mathrm{~mL}$ of water per $1 \mathrm{~g}$ of plant fresh biomass) and suspension was stirred in a Multi-Wrist Shaker at room temperature for two hours and left at $4^{\circ} \mathrm{C}, 24 \mathrm{hrs}$. The plant suspension was filtered through four layers of cheese cloth to remove the gross material, centrifuge at 
$3,000 \mathrm{rpm}$ at $10^{\circ} \mathrm{C}$ for 15 minutes; the supernatant was recovered and treated as the aqueous extract. Finally it was filtered under sterile conditions through $0.45 \mu \mathrm{m}$ nylon sterile filters to render the solution sterile and it was keep frozen for the lettuce bioassays.

\section{Acetone extract procedure}

Thirty grams of fresh $C$. demersum biomass were homogenized in mortar and pestle until obtain a soft plant mass. $50 \mathrm{~mL}$ of $50 \%$ acetone was added to this biomass and the suspension was stirred in a Multi-Wrist Shaker at room temperature for two hours, it was filtered through four layers of cheese cloth to remove the gross material and the acetone evaporated in water bath at 37$40^{\circ} \mathrm{C}$. After this procedure, the suspension was centrifuged at $3,000 \mathrm{rpm}$ at $10^{\circ} \mathrm{C}$ for 15 minutes to recover the supernatant and treated as the acetone extract. Finally it was filtered under sterile conditions through $0.45 \mu \mathrm{m}$ nylon sterile filters to render the solution sterile and it was keep frozen for the lettuce bioassays.

\section{Bioassay to test the bioactivity of $C$. demersum extracts}

Fifteen commercially available seeds of Lactuca sativa L. were surface-sterilized with $10 \%$ sodium hypochlorite and then thoroughly rinsed with sterile distilled water and placed in Petri dishes with sterile filter paper of medium pore, in each experimental conditions considered: control seeds with $0.7 \mathrm{~mL}$ of distilled deionized and sterile water and $0.7 \mathrm{~mL}$ of each diluted aqueous and $50 \%$ acetone extracts (in $10 \mathrm{~mL}$ of distilled deionized and sterile water, total volume) taking: 5, 10, $15,25,50,200$ and $300 \mu \mathrm{L}$ of each one. Petri dishes were sealed with Parafilm to prevent water loss and incubated in dark at room temperature $\left(30^{\circ} \mathrm{C}\right)$ for five days. All the experiments were performed by quintuplicate and after incubation; the percent germination and length of radicles (primary root) were recorded. The bioactivity of both $C$. demersum extracts was analyzed by various expressions; Relative Root Elongation (RRE, \%), calculated according to Zhang et al. (2013), using the equation:

\section{$\mathrm{RRE}=\mathrm{REext} / \mathrm{REc} \times 100$}

Where, REext is the root length measured in seddlings exposed to both $C$. demersum extracts and REc is the root length measured in the control seedlings. The toxicity of both extracts was measured according to Bagur-González et al. (2011), by the Normalized Residual Percentage of Germinated Seeds Index
(NRPGI) following the equation:

$$
\mathrm{NRPGI}=\mathrm{Gext}-\mathrm{Gc} / \mathrm{Gc}
$$

Where, Gext is the average number of germinated seeds in $C$. demersum extracts (\%), and $\mathrm{Gc}$ is the average number of germinated seeds in the control (\%) and by the Normalized Residual Elongation Root Index (NRERI) following the equation:

\section{$\mathrm{NRERI}=\mathrm{REext}-\mathrm{REc} / \mathrm{REc}$}

Where, REext is the average length of the root seedlings in $C$. demersum extracts $(\mathrm{cm})$ and $\mathrm{REc}$ is the average length of the root seedlings in the control $(\mathrm{cm})$.

The use of these indices allows the analysis of extracts' toxicity; where values can vary from -1 (maximum phytotoxicity) to $>0$, using the scale proposed by BagurGonzález et al. (2011), to make a good classification of this effect, as follows; $\mathrm{A}=0$ to -0.25 low toxicity, $\mathrm{B}=$ -0.25 to -0.5 moderate toxicity, $\mathrm{C}=-0.5$ to -0.75 high toxicity and $\mathrm{D}=-0.75$ to -1 very high toxicity. Values $>0$ indicated a stimulation of the growth named as hormesis.

All data obtained were analyzed by one-way analysis of variance and the mean differences were compared applying a Tukey-Kramer Method using the statistics program Graph Pad Instat Ver. 2.03.

\section{Results and discussion}

Nature of $C$. demersum extracts and their bioactivity on $L$. sativa seedlings

In this study, $C$. demersum extracts were prepared according Gross et al. (2003) to optimize the extraction procedure of active compounds as they recommended from freeze-material; according to the solvent employed (acetone) for extraction, the extract may present two active fractions: one more hydrophilic and one moderately lipophilic. Also, according to Macías et al. (2008), massive extracts with organic solvents (maceration for long time periods, extraction of ground or powdered samples) allows to obtain most of the secondary metabolites present in the organism and exudates should be the best choice of crude extracts to work with, as they are the major source of chemicals released into the environment. In this study, aqueous extract inhibited lettuce germination compared to the control seeds (Table 1); this inhibition increase as the aqueous extract increased with a statistical significance 
of inhibition at $50 \mu \mathrm{L}$ of aqueous extract $(59.99 \pm 15.6$, $p<0.05) .50 \%$ acetone extract diminished the germination percentage of $L$. sativa seeds, mainly with 15,25 and $50 \mu \mathrm{L}$ aliquots of acetone extract $(51.11 \pm 15.3$, $31.16 \pm 14.7$ and $59.99 \pm 12.1$, respectively).

The root growth inhibition or promotion is a good indicator of the seedlings response to active compounds; in this work, the aqueous extract of $C$. demersum diminished the root length of $L$. sativa seedlings compared to control seedlings (Fig. 1a); results of root length of $L$. sativa seedlings exposed to $C$. demersum $50 \%$ acetone extract (Fig. 1b), showed a marked differences between the aliquots of this extract regarding to the root growth inhibition. Quayyum et al. (1999) noted that water extracts of some aquatic plants inhibited the primary root growth of lettuce as well as total root length seedlings and this sensitivity of $L$. sativa could be related to the leachates or extracts of the aquatic species tested.

Table 1. Germination percentage (\%) of Lactuca sativa seeds exposed to Ceratophyllum demersum extracts*

\begin{tabular}{|c|c|c|c|c|c|c|c|}
\hline \multicolumn{8}{|c|}{ Ceratophyllum demersum aqueous extract } \\
\hline Control & $5 \mu \mathrm{L}$ & $10 \mu \mathrm{L}$ & $15 \mu \mathrm{L}$ & $25 \mu \mathrm{L}$ & $50 \mu \mathrm{L}$ & $200 \mu \mathrm{L}$ & $300 \mu \mathrm{L}$ \\
\hline $89.33 \pm$ & $81.33 \pm$ & $77.33 \pm$ & $81.33 \pm$ & $81.33 \pm$ & $59.99 \pm$ & $78.66 \pm$ & $65.33 \pm$ \\
\hline $2.11 \mathrm{a}$ & 15.91 & 13.8 & 11.92 & 11.9 & $15.6 \mathrm{a}$ & 11.92 & 9.88 \\
\hline \multicolumn{8}{|c|}{ Ceratophyllum demersum $50 \%$ acetone extract } \\
\hline Control & $5 \mu \mathrm{L}$ & $10 \mu \mathrm{L}$ & $15 \mu \mathrm{L}$ & $25 \mu \mathrm{L}$ & $50 \mu \mathrm{L}$ & $200 \mu \mathrm{L}$ & $300 \mu \mathrm{L}$ \\
\hline 89.33 & $83.33 \pm$ & $86.66 \pm$ & $51.11 \pm$ & $31.66 \pm$ & $59.99 \pm$ & $69.33 \pm$ & $69.33 \pm$ \\
\hline $\pm 12.11 \mathrm{a}, \mathrm{b}, \mathrm{c}$ & $11.54 \mathrm{a}, \mathrm{c}$ & $9.42 \mathrm{a}, \mathrm{c}$ & $15.39 \mathrm{a}, \mathrm{b}$ & $14.78 \mathrm{c}, \mathrm{b}$ & $12.17 \mathrm{a}$ & $10.11 \mathrm{~b}$ & $13.82 \mathrm{~b}$ \\
\hline
\end{tabular}

$* n=60$. Mean values \pm S.D. from quintuplicates are given. The different lower-case letters show the significant differences found $(p<0.001)$.



Fig. 1: Root length (cm) of Lactuca sativa L. seedlings.

1a) Ceratophyllum demersum L. aqueous extract, 1b) Ceratophyllum demersum L. $50 \%$ acetone extract. $(n=60$, the different lower-case letters shows the significant differences founded $[p<0.001])$.
Relative root elongation of $L$. sativa seedlings: particularly the response against $C$. demersum extracts

Aliquots of $5,10,15$ and $25 \mu \mathrm{L}$ of aqueous extract maintained the RRE of L. sativa seedlings, between 70 to $85 \%$ and aliquots of 50,200 and $300 \mu \mathrm{L}$ of this extract diminished the RRE from 85 to $60 \%$ compared to the RRE of control seedlings; in contrast, to the results obtained from the exposition of $L$. sativa seedlings to aqueous extract, the RRE of seedlings were stimulated by the 10,15 and $25 \mu \mathrm{L}$ aliquots of $50 \%$ acetone extract, with 125, 160 and 130\%, respectively (Fig. 2). Regarding to some morphological changes observed in seedlings of $L$. sativa, like shortening of root length as Ngoc-Bich and Kato-Noguchi (2012) mention, in this study these changes were observed in experiments of $L$. sativa seeds exposed to the highest aliquots tested of both extracts (Figs. 3 and 4), these observations agree with these authors, who demonstrated that morphological changes of seedling growth provide important information in evaluating the effect of a phytotoxin.

\section{Dose-response relationship between $C$. demersum extracts and $L$. sativum seedlings root growth}

In this study, the comparison of the two indices proposed by Bagur-González et al. (2011): NRPGI and NRERI (Table 2), indicates that the effect of water aqueous 
extract aliquots from $C$. demersum on germination of $L$. sativa seeds showed a low toxicity in aliquots of 5 to $50 \mu \mathrm{L}$; the diminished in germination percentage of seeds in experiments with 200 and $300 \mu \mathrm{L}$ aliquots of aqueous extract as the NRPGI index have a moderate toxicity on L. sativa seeds. Regarding to the 5 to $25 \mu \mathrm{L}$ and $200 \mu \mathrm{L}$ aliquots of $50 \%$ acetone extract added to L. sativa seeds, values of NRPGI index also showed a low toxicity effect as the effect of aqueous extract, but with less magnitude. Aliquots of 50 and $300 \mu \mathrm{L}$ of $50 \%$ acetone extract showed a moderate toxicity on germination of $L$. sativa seeds.

Table 2. Determination of NRERI and NRPGI indices from Ceratophyllum demersum extracts*

\begin{tabular}{lll}
\hline NRERI index & & \\
\hline Aliquots & Aqueous extract & Acetone extract \\
\hline $5 \mu \mathrm{L}$ & A, -0.2497 & E, 0.0706 \\
$10 \mu \mathrm{L}$ & A, -0.1279 & E, 0.3057 \\
$15 \mu \mathrm{L}$ & $\mathrm{A},-0.1335$ & E, 0.5596 \\
$25 \mu \mathrm{L}$ & $\mathrm{A},-0.0114$ & E, 0.3022 \\
$50 \mu \mathrm{L}$ & $\mathrm{A},-0.1468$ & $\mathrm{~B},-0.2524$ \\
$200 \mu \mathrm{L}$ & $\mathrm{B},-0.4216$ & $\mathrm{~B},-0.34973$ \\
$300 \mu \mathrm{L}$ & $\mathrm{B},-0.2619$ & $\mathrm{~B},-0.37745$ \\
\hline NRPGI index & & \\
\hline Aliquots & Aqueous extract & Acetone extract \\
\hline $5 \mu \mathrm{L}$ & $\mathrm{A},-0.0895$ & $\mathrm{~A},-0.0671$ \\
$10 \mu \mathrm{L}$ & $\mathrm{A},-0.1343$ & $\mathrm{~A},-0.0298$ \\
$15 \mu \mathrm{L}$ & $\mathrm{A},-0.0895$ & $\mathrm{~B},-0.4278$ \\
$25 \mu \mathrm{L}$ & $\mathrm{A},-0.0895$ & $\mathrm{C},-0.6455$ \\
$50 \mu \mathrm{L}$ & $\mathrm{B},-0.3283$ & $\mathrm{~B},-0.3284$ \\
$200 \mu \mathrm{L}$ & $\mathrm{A},-0.1193$ & $\mathrm{~A},-0.2238$ \\
$300 \mu \mathrm{L}$ & $\mathrm{B},-0.2686$ & $\mathrm{~A},-0.2239$ \\
\hline
\end{tabular}

*Where: $\mathbf{A}=0$ a -0.25 low toxicity, $\mathbf{B}=-0.25$ a -0.5 moderate toxicity, $\mathbf{C}=-0.5$ a -0.75 high toxicity, $\mathbf{D}=-0.75$ a -1.0 very high toxicity y $\mathbf{E}=>0$ hormesis (Bagur-González et al., 2011).

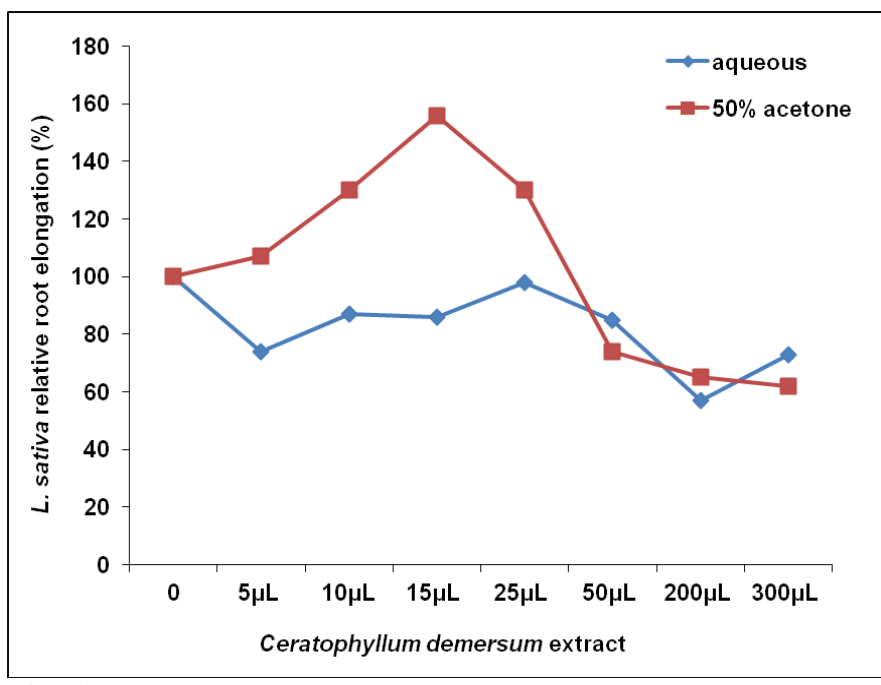

Fig. 2: Relative root elongation (RRE, \%) of Lactuca sativa L. seedlings, against aliquots of Ceratophyllum demersum L. extracts.

In this study, the most sensitive index was NRERI, where the phytotoxicity of both extracts in lettuce seedlings was directly related to the nature of them; aliquots of $50 \%$ acetone extract showed a negative effect on root promotion, from A to $\mathrm{C}$, in Bagur-González et al. (2011) categories; low toxicity produced by aliquots 5 , 10,200 and $300 \mu \mathrm{L}(-0.06,-0.02,-0.22$ and -0.22 , respectively); moderate toxicity by aliquots 15 and $50 \mu \mathrm{L}$ $(-0.42$ and -0.32 , respectively) and very toxic effect on root elongation of $L$. sativa seedlings produced by aliquots of $25 \mu \mathrm{L}(-0.64)$.

In this study, the NRERI obtained by the presence of aqueous extract aliquots showed a promotion on root elongation with $5,10,15$ and $25 \mu \mathrm{L}$ aliquots of aqueous extract with $0.07,0.30,0.55$ and 0.30 values, respectively; this response was agree with Ngoc-Bich and Kato-Noguchi (2012) results, where the concentration-response relationship in growth of Echinochloa crus-galli L. Beauv., Lolium multiforum Lam., Medicago sativa L., Lepidium sativum $\mathrm{L}$. and Lactuca sativa $\mathrm{L}$. species, was according to hormesis response, a phenomenon that is characterized by low-dose stimulation and high-dose inhibition. 

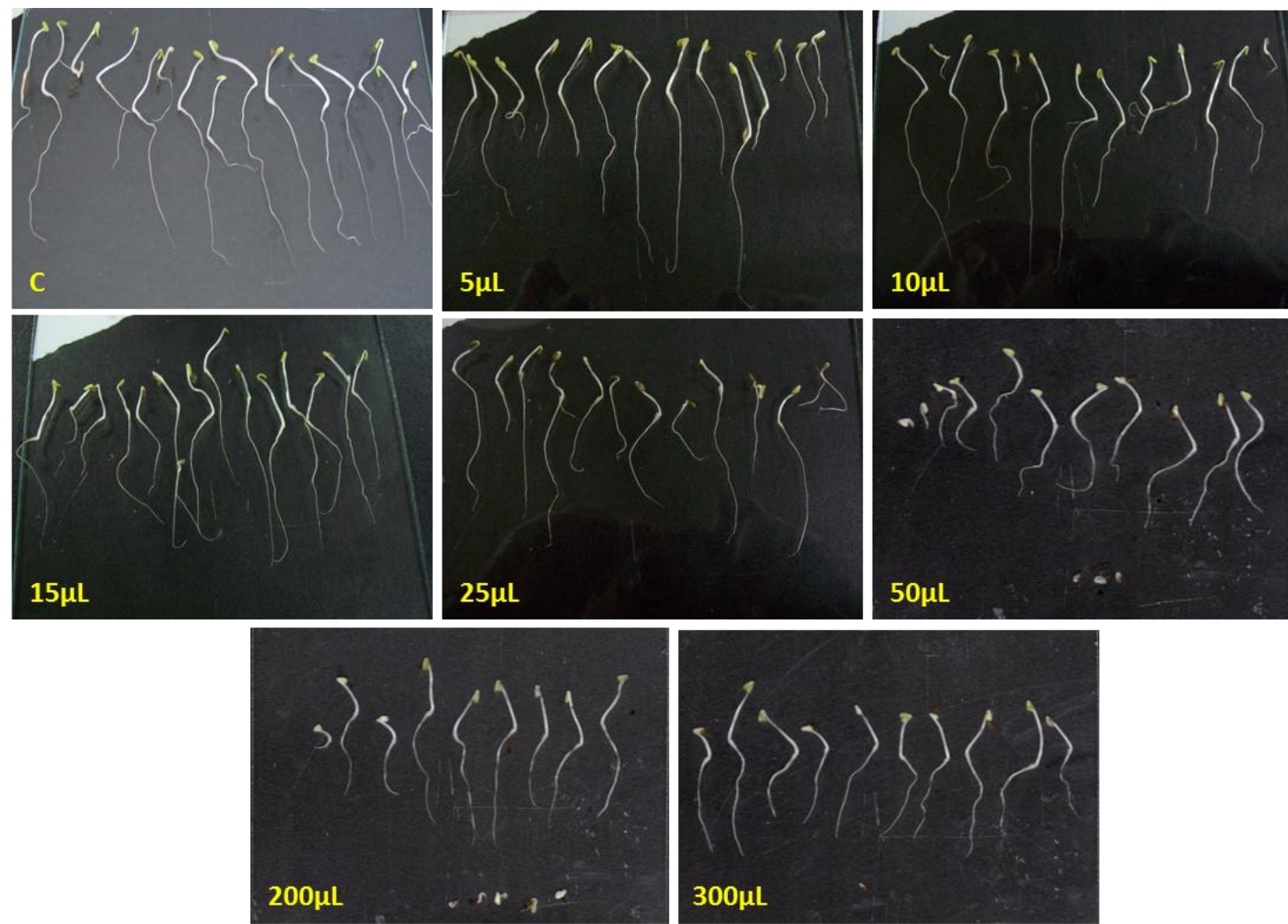

Fig. 3: Lactuca sativa $\mathrm{L}$. seedlings appearance after five days exposed to aliquots of Ceratophyllum demersum $\mathrm{L}$. aqueous extract $(\mathrm{C}=$ control seedlings $)$.


Fig. 4: Lactuca sativa L. seedlings appearance after five days exposed to aliquots of Ceratophyllum demersum $\mathrm{L} .50 \%$ acetone extract $(\mathrm{C}=$ control seedlings $)$. 
The NRERI obtained by the presence of aliquots 50, 200 and $300 \mu \mathrm{L}$ of aqueous extract diminished root elongation of $L$. sativa seedlings $(-0.25,-0.34$ and -0.37 , respectively) showing a high dose inhibition effect. It is important to comment that hormesis a well-recognized phenomenon in the study of allelopathy in terrestrial plants (Randhawa et al., 2002; Liu et al., 2003; Belz et al., 2004; Ahmed et al., 2007; Regina et al., 2007).

Finally, it is important to mention that plant biomarkers offer advantages as the assessment of endpoints like germination rate and relative root elongation (BagurGonzález et al. 2011) and allelochemicals may interfere with various physiological processes of the target plant (Pellisier, 2013), that can explain inhibition (or promotion) of plants development as germination (Prati and Bossdorf, 2004; Kadioglu et al., 2005), therefore it is necessary to distinguish between allelopathy and phytotoxicity and as Elakovich and Yang (1996) mention, not all phytotoxic compounds are allelochemicals, even though allelochemicals need to be phytotoxic and consequently, the employ of bioassays with plant extracts are useful to detect active compounds, but not enough to demonstrate an allelopathic behaviour.

\section{Conclusion}

In this study, the effect of two kind of Ceratophyllum demersum extracts: aqueous and 50\% acetone extracts, showed the presence of active compounds that inhibited and promoted the first stage of development in Lactuca sativa seedlings; where the comparison of the NRPGI and NRERI indices applied to this bioassay, indicates doses with low or moderate toxicity and hormesis on this plant species, and the most sensitive toxicity index was NRERI that allows the analysis of the nature of $C$. demersum extracts with bioactive potential.

\section{Conflict of interest statement}

Authors declare that they have no conflict of interest.

\section{Acknowledgement}

Authors are grateful to the Research Project SIP: 20141314 of the Secretaría de Investigación y Posgrado del Instituto Politécnico Nacional, for providing the facilities to carry out this work and also wish to thank for the fellowships from Comisión de Operación y Fomento de Actividades Académicas (COFAA, I.P.N.), EDI (Estímulo al Desempeño de los Investigadores, I.P.N.) and SNI-CONACYT.

\section{References}

Ahmed, R., Uddin, M.B., Khan, M.A.S.A, Mukul, S.A., Hossain, M.K., 2007. Allelopathic effects of Lantana camara on germination and growth behavior of some agricultural crops in Bangladesh. J. For. Res. 18, 301-304.

Bagur-González, M.G., Estepa-Molina, C., Martín-Peinado, F., Morales-Ruano, S., 2011. Toxicity assessment using Lactuca sativa L. bioassay of the metal (loid)s As, Cu, $\mathrm{Mn}, \mathrm{Pb}$ and $\mathrm{Zn}$ in soluble-in-water saturated soil extracts from an abandoned mining site. J. Soils Sediments. 11, 281-289.

Belz, R.G., Hurle, K.J., 2004. A novel laboratory screening bioassay for crop seedling allelopathy. Chem. Ecol. 30, 175-198.

Callaway, R., Ridenour, W., 2004. Novel weapons: invasive success and the evolution of increased competitive ability. Front. Ecol. Environ. 2, 436-443.

Chen, C., Zhou, Q., Bao, Y., Li, Y., Wang, P., 2010. Ecotoxicological effects of polycyclic musks and cadmium on seed germination and seedling growth of wheat (Triticum aestivum). J. Environ. Sci. 22, 1966-1973.

Di Salvatore, M., Carafa, A.M., Carratù, G., 2008. Assessment of heavy metals phytotoxicity next term using seed germination and root elongation tests: a comparison of two growth substrates. Chemosphere.73,1461-1464.

Elakovich, S.D., 1999. Bioassays applied to allelopathic herbaceous vascular hydrophytes. In: Principles and Practices in Plant Ecology: Allelochemical Interactions (Ed.: Inderjit, K. M., Dakshini, M., Foy, C.L.). CRC Press, Boca Raton, FL. pp. 45-56.

Elakovich, S.D., Wooten, J.W., 1989. Allelopathic potential of sixteen aquatic and wetland plants. J. Aquat. Plant Manage. 27, 78-84.

Elakovich, S.D., Yang, J., 1996. Structures and allelopathic effects of Nuphar alkaloids: nupharolutine and 6,6 dihydroxythiobinupharidine. J. Chem. Ecol. 22, 22092219.

Erhard, D., Gross, E.M., 2006. Allelopathic activity of Elodea canadensis and $E$. nuttallii against epiphytes and phytoplankton. Aquat. Bot. 85, 203-211.

Espen, L., Pirovano, L., Cocucci, S.M., 1997. Effect of Ni+ during the early phases of radish (Raphanus sativus) seed germination. Environ. Exp. Bot. 38,187-197.

Fletcher, J.S., Johnson, F.L., McFalane, J.C., 1988. Database assessment of phytotoxicity data published on terrestrial vascular plants. Environ. Toxicol. Chem. 7, 615-622.

Fletcher, R., Renney, A., 1963. A growth inhibitor found in Centaurea spp. Can. J. Plant Sci. 43,475-481.

Gopal, B., Goel, U., 1993. Competition and allelopathy in aquatic plant communities. Bot. Rev. 59, 155-210.

Gross, E. M., 1999. Allelopathy in benthic and littoral areas: case studies on allelochemicals from benthic cyanobacteria and submersed macrophytes. In: Principles and Practices in Plant Ecology: Allelochemical Interactions (Ed.: Inderjit, K.M., Dakshini, M., Foy, C.L.), CRC Press, Boca Raton, FL. pp. 179-199. 
Gross, E.M., Erhard, D., Iványi, E., 2003.Allelopathic activity of Ceratophyllum demersum L. and Najas marina ssp. intermedia (Wolfgang) Casper. Hydrobiologia. 506, 583589.

Gross, E.M., Hilt, S., Lombardo, P., Mulderij, G., 2007. Searching for allelopathic effects of submerged macrophytes on phytoplankton-state of the art and open questions. Hydrobiologia. 584, 77-88.

Gross, E.M., Meyer, H., Schilling, G., 1996. Release and ecological impact of algicidal hydrolyzable polyphenols in Myriophyllum spicatum. Phytochemistry. 41, 133-138.

Hutchinson, G.E., 1975. A Treatise on Limnology. Vol III. Limnological Botany. John Wiley \& Sons, New York.

Jasser, I., 1994. Influence of Ceratophyllum demersum on phytoplankton community in experimental conditions. Verh. Int. Ver. Theor. Angew. Limnol. 25, 2291-2295.

Jasser, I., 1995. The influence of macrophytes on a phytoplankton community in experimental conditions. Hydrobiologia. 306, 21-32.

Kadioglu, I., Yanar, Y., Asav, U., 2005. Allelopathic effects of weeds extracts against seed germination of some plants. J. Environ. Biol. 26,169-173.

Kočí, V., Mocová, K., Kulovaná, M., Vosáhlová, S., 2010. Phytotoxicity tests of solid wastes and contaminated soils in the Czech Republic. Environ. Sci. Pollut. Res. 17, 611623.

Kogan, S.I., Chinnova, G.A.,1972. Relations between Ceratophyllum demersum (L.) and some blue-green algae. Hydrobiol. J. 8, 14-19.

Körner, S., Nicklisch, A., 2002. Allelopathic growth inhibition of selected phytoplankton species by submerged macrophytes. J. Phycol. 38, 862-871.

Ling, T., Fangke, Y., Jun, R., 2010. Effect of mercury to seed germination, coleoptile growth and root elongation of four vegetables. Res. J. Phytochem. 4, 225-233.

Liu, D.L., An, M., Johnson, I.R., Lovett, J.V., 2003. Mathematical modeling of allelopathy. III. A model for curve-fitting allelochemical dose responses. Nonlinear. Biol. Toxicol. Med. 1, 37-50.

Macías, F.A., Galindo, L.G.J, García-Díaz, M.D., Galindo, J.C.G., 2008.Allelopathic agents from aquatic ecosystems: potential biopesticides models. Phytochem. Rev.7, 155-178.

Mishra, A., Choudhuri, M.A., 1998. Ameliorant of lead and mercury effect on germination and rice seedling growth by antioxidants. Biol. Plant. 41, 469-473.

Morris, C., Gross, P.R., Call, C.A., 2009. Elemental allelopathy: processes, progress, and pitfalls. Plant Ecol. 202, 1-11.

Mulderij, G., Mau, B., van Donk, E., Gross, E.M., 2007. Allelopathic activity of Stratiotes aloides on phytoplankton towards identification of allelopathic substances. Hydrobiologia. 584, 89-100.

Nasir, H., Iqbal, Z., Hiradate, S., Fujii, Y., 2005.Allelopathic potential of Robinia pseudoacacia L. J. Chem. Ecol. 31, 2179-2192.

Ngoc-Bich, T.T., Kato-Noguchi, H., 2012. Allelopathic Potential of four emergent macrophytes on the growth of terrestrial plant species. Inter. J. Biosci. Biotech. 4, 81-94.

Pellissier, F., 2013. Improved germination bioassays for allelopathy research. Acta Physiol. Plant. 35, 23-30.

Prati, D., Bossdorf, O., 2004. Allelopathic inhibition of germination by Alliaria petiolata (Brassicaceae). Am. J. Bot. 91, 285-288.

Quayyum, H.A., Mallik, A.U., Orr, D.E., Lee, P.F., 1999. Allelopathic potential of aquatic plants associated with wild rice: II. Isolation and identification of allelochemicals. J. Chem. Ecol. 25, 221-228.

Randhawa, M. A., Cheema, Z.A., Ali, M.A., 2002. Allelopathic effect of sorghum water extract on the germination and seedling growth of Trianthema portulacastrum. Int. J. Agric. Biol. 4, 383-384.

Regina, G. B., Reinhardtb, C.F., L.C., Hurle, K.F., 2007. Stimulation versus inhibition-bioactivity of parthenin, a phytochemical from Parthenium hysterophorus L. Crop. Prot. 26, 237-245.

Sharifi, M., Sadeghi, Y., Akbarpour, M., 2007. Germination and growth of six plant species on contaminated soil with spent oil. Int. J. Environ. Sci. Technol. 4,463-470.

Tiqua, S.M., Tam, N.F.Y., Hodgkiss, I.J., 1996. Effect of composting on phytotoxicity of spent pig manure sawdust litter. Environ. Pollut. 93,249-256.

Valerio, M.E., Garcìa, J.F., Peinado, F.M., 2007. Determination of phytotoxicity of soluble elements in soils, based on a biomass with lettuce (Lactuca sativa L.). Sci. Total Environ. 378, 63-66.

Visioli, G., Conti, F.D., Gardi, C., Menta, C., 2014. Germination and root elongation bioassays in six different plant species for testing $\mathrm{Ni}$ contamination in soil. Bull. Environ. Contam. Toxicol. 92, 490-496.

Wang, X., Sun, C., Gao, S., Wang, L., Shuokui, H., 2001. Validation of germination rate and root elongation as indicator to assess phytotoxicity in Cucumis sativus. Chemosphere. 44,1711-1721.

Wium-Andersen, S., Anthoni, U., Houen, G.,1983. Elemental sulphur, a possible allelopathic compound from Ceratophyllum demersum. Phytochemistry. 22, 2613.

Zhang, X., Wang, X., Wei, D., Li, B., Ma, Y., Huang, Z., 2013. The influence of soil solution properties on phytotoxicity of soil soluble copper in a wide range of soils. Geoderma. 211, 1-7.

\section{How to cite this article:}

Viveros-Legorreta, J. L., Sarma, S. S. S., Guerrero-Zúñiga, L. A., Rodríguez-Dorantes, A., 2016. Effect of the nature of Ceratophyllum demersum extracts on Lactuca sativa seedlings. Int. J. Curr. Res. Biosci. Plant Biol. 3(7), 65-72. doi: http://dx.doi.org/10.20546/ijcrbp.2016.307.010 